\title{
Evaluation of Our Food Protein Induced Proctocolitis Cases: A Single Center Experience
}

\author{
Nagehan Aslan ${ }^{1 *}$, Tugba Koca ${ }^{2}$ and Mustafa Akcam² \\ ${ }^{1}$ Department of Pediatrics, Suleyman Demirel University Faculty of Medicine, Isparta, Turkey \\ ${ }^{2}$ Department of Pediatrics, Division of Pediatric Gastroenterology, Hepatology and Nutrition, Suleyman Demirel University Faculty of Medicine, \\ Isparta, Turkey
}

${ }^{*}$ Corresponding author: Nagehan Aslan, Department of Pediatrics, Suleyman Demirel University Faculty of Medicine, Isparta, Turkey, Tel: +0505 54999 86; E-mail: nagehan_aslan@hotmail.com

Rec date: July 18, 2017; Acc date: September 18, 2017; Pub date: September 21, 2017

Citation: Aslan N, Koca T, Akcam M (2017) Evaluation of Our Food Protein Induced Proctocolitis Cases: A Single Center Experience. J Clin Gastroenterol Hepatol Vol.1 No.3:25

\section{Abstract}

Aim: The purpose of this study was to determine clinical characteristics, laboratory findings and course in infants diagnosed with allergic proctocolitis.

Materials and methods: Thirty-four patients diagnosed with food protein-induced proctocolitis in our clinic between 2013 and 2016 were evaluated retrospectively. Files were reviewed in terms of symptoms, clinical features, laboratory findings and responses to treatment.

Results and discussion: Sixteen (47\%) patients were female. Mean age was $3.3 \pm 2.3$ months (1-10 months). Eleven (32.3\%) cases presented with pronounced rectal bleeding and $23(67.6 \%)$ with bloody spots or streaks in stool. In terms of nutrition, $76.4 \%$ of babies were receiving breast milk alone, and the remainder received breast milk with supplementary formula. Mean peripheral eosinophil rate was $8.6 \pm 6.3 \%$. Response was achieved solely by removal of milk and dairy products from the mother's diet in 25 (73.5\%) cases, while multiple allergen food (eggs, nuts, fish etc.) elimination was applied to mothers in 8 (23.5\%) and breast milk was discontinued for 3 months in one case. Symptoms resolved in a mean $6.4 \pm$ 5.9 days (1-25) following of elimination diet.

Conclusion: Our study shows that allergic proctocolitis in infancy frequently appears in exclusively breastfed babies, that the condition has a benign course and that cow's milk protein plays an important role in the etiopathogenesis.

Keywords: Allergic proctocolitis; Food allergy; Food protein-induced proctocolitis; Infant; Rectal bleeding

\section{Introduction}

The prevalence of food allergies is increasing worldwide and is becoming a major public health problem [1]. The prevalence of allergic reactions to food proteins in infants is $2 \%$ to $8 \%$ [2].
Food protein-induced proctocolitis is also known as allergic proctocolitis (AP) and results from a non-IgE-mediated allergic reaction. $A P$ is a widespread clinical entity, although the exact prevalence is still unclear [3]. AP manifests with mucus or blood in the stool, and particularly in healthy appearing infants who are exclusively breastfed [4,5]. However, it may also manifest with diarrhea, vomiting, irritability, abdominal distension and delayed growth [6]. Diagnosis is based on history, clinical findings, improvement after dietary therapy and the "challenge" test $[7,8]$. The purpose of this study was to examine clinical features and laboratory characteristics including mean platelet volume (MPV) and the neutrophil-tolymphocyte ratio (NLR) in patients diagnosed with $A P$, in the light of the current literature.

\section{Materials and Methods}

The records of patients monitored in our clinic with a diagnosis of AP between January 2013 and April 2016 were evaluated respectively. Diagnosis of AP in presentations with rectal bleeding was based on resolution of symptoms following elimination diet and recurrence of symptoms with an oral food challenge, following exclusion of other potential causes such as infection, necrotizing enterocolitis, Hirschsprung's disease and volvulus. Patients' demographic characteristics, type of rectal bleeding (streaks/pronounced rectal bleeding), presence of accompanying extraintestinal findings (atopic skin findings/ wheezing), nutrition history (breast milk/formula), history of antibiotic use in other health centers where patients presented due to rectal bleeding, responses to and durations of elimination diet, presence of anal fissure at physical examination, complete blood count, C-Reactive protein (CRP), erythrocyte sedimentation rates (ESR), absolute eosinophil count, MPV, NLR values and stool microscopy and culture results were recorded. A control group consisting of 30 patients matched with the control group in terms of age and sex was established, and MPV and NLR were compared.

The data obtained were transferred onto and analyzed on SPSS 16.0 software. Continuous variables were expressed as mean \pm standard deviation and categoric variables as number and percentage (\%). The Mann-Whitney $U$ test was used to 
compare non-normally distributed numeric variables. $p<0.05$ was regarded as statistically significant. Approval for the study was taken from the Suleyman Demirel University ethics committee of clinical research.

\section{Results}

The records of 41 patients with AP were retrieved in this period, and these were investigated retrospectively. Five patients whose files were incomplete were excluded, and the study was completed with 36 patients. Characteristics of cases are shown in Table 1.

Table 1: Characteristic features of cases ( $n: 33)$.

\begin{tabular}{|c|c|}
\hline Variables & n (\%) \\
\hline Age (months) & $3.2 \pm 2.3$ \\
\hline $\mathrm{F} / \mathrm{M}$ & $17(47.3) / 19(52.7)$ \\
\hline Time to resolution of symptoms (days) & $6.1 \pm 5.9$ \\
\hline \multicolumn{2}{|l|}{ Presentation symptoms } \\
\hline Pronounced rectal bleeding & $11(30.5)$ \\
\hline Streak/spot type bleeding & $25(69.5)$ \\
\hline $\begin{array}{l}\text { Accompanying GIS symptoms (vomiting, diarrhea } \\
\text { with mucus) }\end{array}$ & $5(13.8)$ \\
\hline $\begin{array}{l}\text { Extraintestinal findings (atopic skin findings, } \\
\text { wheezing) }\end{array}$ & $16(44.4)$ \\
\hline \multicolumn{2}{|l|}{ Laboratory results } \\
\hline $\begin{array}{l}\text { Peripheral eosinophilia }(>6 \%) / \text { Absolute eosinophil } \\
\text { count }\left(>450 \mathrm{~mm}^{3}\right)\end{array}$ & $22(61.1)$ \\
\hline Thrombocytosis $\left(450,000-700,000 / \mathrm{mm}^{3}\right)$ & $12(33.3)$ \\
\hline Anemia ( $\mathrm{Hb}$ below normal value) & $4(11.1)$ \\
\hline Mean MPV & $8.2 \pm 0.99 \mathrm{fL}$ \\
\hline NLR & $38.5 \pm 20.2 \%$ \\
\hline
\end{tabular}

Seventeen (47.3\%) patients were female and 19 (52.7\%) male. Mean age at presentation was $3.2 \pm 2.3$ months (1-10). Eleven $(30.5 \%)$ patients presented with pronounced rectal bleeding and 25 (69.5\%) with stripe/spot type blood in stool. In addition, extra-intestinal findings such as skin rash and/or wheezing were present in 16 (44.4\%) cases. Vomiting and/or diarrhea with mucus as accompanying gastrointestinal system symptoms were present in $5(13.8 \%)$ cases.

In terms of nutrition, $\mathbf{7 7 . 7 \%}$ of infants were receiving only breast milk, with the remainder receiving formula support in addition to breast milk. Seven (19.4\%) had a history of antibiotic therapy with diagnosis of amebic dysentery at other health centers.

All patients were healthy in appearance, and growth and development were normal. Systemic examination was normal in all cases except for presence of anal fissure in 8 (22.2\%) patients.
Eosinophilia was present in $22(61.1 \%)$ patients. Mean eosinophil rate at complete blood count was $8.6 \pm 6.3 \%$, ranging from $2 \%$ to $26 \%$. Mean absolute eosinophil count was $904 \pm 727 / \mathrm{mm}^{3}$ (162-3075). Hemoglobin levels were slightly below normal only in $4(11.1 \%)$ patients. Mild thrombocytosis $\left(<700,000 / \mathrm{mm}^{3}\right)$ was determined in $12(33.3 \%)$ patients. Patients' mean MPV value was $8.2 \pm 0.99 \mathrm{fL}$. This did not differ statistically significantly compared to the control group $(p=0.95)$. Mean NLO value in the study group was $38.5 \pm$ $20.2 \%$. No statistically significant difference was again determined compared to the control group $(p=0.33)$. No elevation in CRP or ESR, leukocytosis or pathogen in stool culture was observed in any patient.

Eosinophil in stool smear was investigated in 7 (19.4\%) patients, and all were positive (Figure 1). Histopathology was compatible with eosinophilic proctocolitis in 2 patients whose undergoing rectal biopsy.

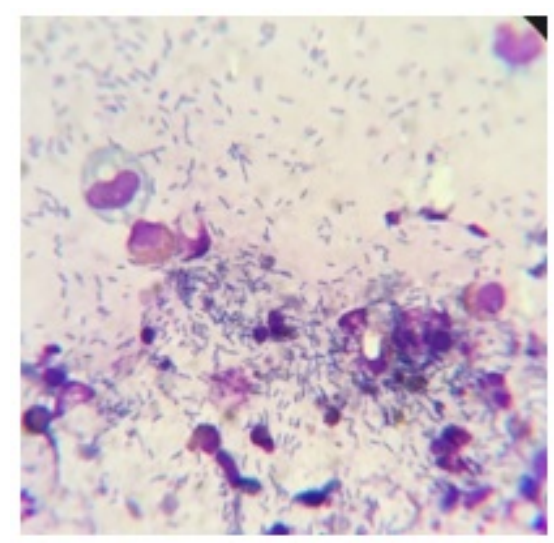

Figure 1: Eosinophil in stool examination at microscopic.

Symptoms resolved entirely with elimination of cow's milk and milk products from the mother's diet in 27 (75\%) cases, while symptoms resolved with elimination of various allergenic foods (eggs, nuts and fish) in 8 (22.2) cases.

Table 2: Treatment regimens leading to resolution ( $\mathrm{n}: 33)$.

\begin{tabular}{|l|c|}
\hline Treatment regime & $\mathbf{n}(\%)$ \\
\hline $\begin{array}{l}\text { Elimination of cow's milk+milk products from the mother's } \\
\text { diet }\end{array}$ & $27(75)$ \\
\hline $\begin{array}{l}\text { Elimination of multiple allergen foods (eggs, nuts, fish and } \\
\text { meat) from the mother's diet }\end{array}$ & $8(22.2)$ \\
\hline Discontinuation of mother's milk & $1(2.7)$ \\
\hline $\begin{array}{l}\text { Mother's milk+elementary formula during the supplementary } \\
\text { nutrition period }\end{array}$ & $25(69.4)$ \\
\hline Mother's milk + extensively hydrolyzed formula & $17(68)$ \\
\hline Mother's milk+ amino acid-based formula & $8(32)$ \\
\hline
\end{tabular}

In one case, breast milk had to be discontinued since symptoms failed to improve despite multiple allergen food elimination from the mother's diet. The symptoms then improved, but rectal bleeding recurred when breast milk was 
again given after 1 week. Breast milk was therefore discontinued for 3 months. Twenty-five (69.4\%) patients started on formula and supplementary foods in addition to breast milk during monitoring were started on elementary formulas. Seventeen (68\%) of these were given extensively hydrolyzed formula and 8 (32\%) were given amino acid-based formula (Table 2).

Mean time to improvement of symptoms following commencement of elimination diet was $6.1 \pm 5.9$ days (1-25), and this diet was maintained for at least 6 months in all cases. Allergen foods were reintroduced at the end of 6 months. Elimination diet was maintained until at least 1 year of age in cases in which symptoms persisted.

In terms of patient distribution by years, the number of diagnosed cases increased over the years (Figure 2).

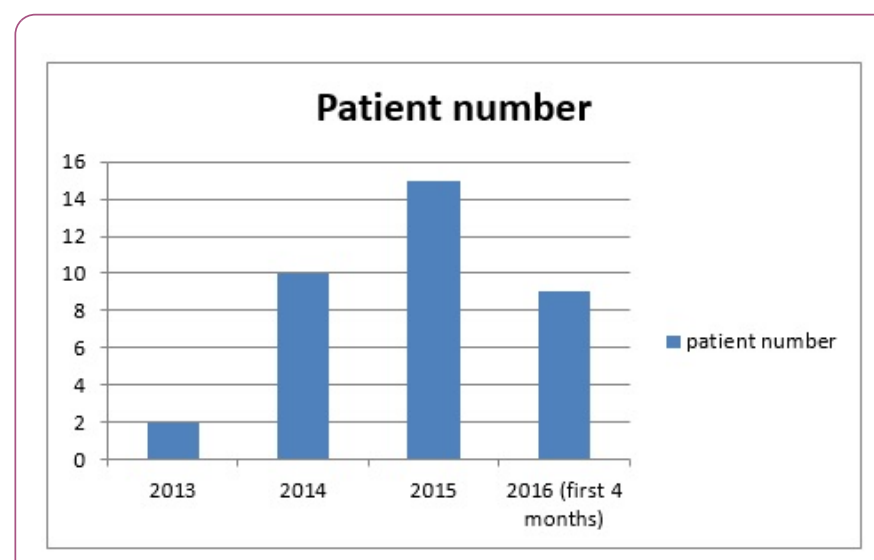

Figure 2: Patient distribution by years.

\section{Discussion}

AP is one of the most common causes of rectal bleeding in the form of spots or streaks inside the stool in early infancy and may manifest, albeit rarely, as pronounced rectal bleeding [9]. In agreement with the literature, the most common cause of presentation in our study was bloody streaks or spots.

Findings usually appear between 2 and 8 weeks [10]. Mean age at diagnosis in our cases was $3.2 \pm 2.3$ months, with 16 $(44.4 \%)$ cases presenting before 8 weeks. We attribute the later age at diagnosis compared to that in the literature to patients having spent time in primary and secondary health institutions before diagnosis and thus presenting to us late.

These infants have a healthy appearance despite diarrhea and rectal bleeding, and delayed growth and interrupted weight gain are not generally to be expected [11]. Our cases were also infants with a healthy appearance, and no growth delay was observed in any patients. Fissure or erythema accompanying AP may be determined at anal examination [12]. Fissure was determined in $22.2 \%$ of our cases. Frequent defecation and stool $\mathrm{pH}$ alteration may play a role in fissure development.

A history of taking antibiotic therapy with a diagnosis amebic dysentery at other health centers based on bloody stool was present in $7(19.4 \%)$ cases. This may threaten the baby's health by compromising the intestinal flora and also result in unnecessary economic costs.

More than $60 \%$ of infants diagnosed with AP are exclusively breastfed babies, the remainder also receiving supplementary foods containing cow's milk protein or soya [5]. The great majority of our cases $\mathbf{( 7 7 . 7 \% )}$ were exclusively breastfed babies.

AP developing in association with food proteins is a non-lgEmediated allergic reaction, the most common cause of which is cow's milk protein [2]. However, AP has also been associated with food proteins such as eggs, soya, fish and meat [13]. No clinical improvement was observed in $25 \%$ of our patients with elimination of cow's milk and milk products only from the mother's diet, and additional elimination of eggs, nuts, fish and meat was required.

There is no sensitive laboratory test capable of use in the diagnosis of AP. Skin tests and specific IgE levels are also negative. Anemia or hypoalbuminemia are rarely determined, while peripheral eosinophilia is observed in approximately half of patients $[6,14]$. Most babies' results are also normal $[4,10]$. Mild anemia develops in infants with continued bleeding, but is rarely significant at initial examination [15]. Eosinophilia was observed in $61.1 \%$ of our cases, and hemoglobin values were slightly below normal in $11.1 \%$. Reports of thrombocytosis in cases of AP have found in the literature [16]. Mild thrombocytosis was determined in 12 (33.3\%) of our cases, and this was interpreted as a nonspecific inflammation finding of AP.

The NLR is an easily available and economical method that can be used in the diagnosis of disease with an inflammatory component $[17,18]$. Previous studies have reported a change in favor of neutrophils in gastrointestinal bleeding in HenochSchönlein purpura and in diseases such as allergic rhinitis, asthma and juvenile idiopathic arthritis $[19,20]$. We also investigated the NLR in our patients and determined a change in favor of lymphocytes, similarly to the control group. Similarly, mean MPV in the study group did not differ significantly from that in the control group. To the best of our knowledge, there are no previously published reports concerning MPV or NLR in patients with AP. It is not therefore possible to discuss these results in the light of the literature.

Endoscopic and colonoscopic examinations are not recommended for diagnosis [21]. Rectal biopsy was performed in only two patients in our study. Histopathological examination revealed eosinophilic proctocolitis. Investigation of eosinophils in the stool smear is a more specific and easier method for the diagnosis of AP colitis. Eosinophils are believed to be directly responsible for the tissue injury in this disease [22]. In the current study, stool smear was performed with seven patients, and eosinophil was determined in all these cases.

The basic approach in the treatment of AP consists of eliminating the responsible food allergen from the diet [23]. Most exclusively breastfed infants improve when cow's milk and milk products are eliminated from the mother's diet. 
Improvement in refractory cases can also be achieved with the elimination of allergen foods such as soya, egg and fish. If the mother is not compliant with the diet, if the allergen protein cannot be identified and eliminated or if the baby is receiving cow's milk-based formula, then the diet can be adjusted to fully hydrolyzed or amino acid-based. In our study, amelioration was achieved in the majority of babies (75\%) with the elimination of milk and milk products from the mother's diet, while in some (22.2\%) clinical improvement was achieved with the elimination from diet of eggs, nuts, fish and meat. In one case, who was refractory to diet, breast milk was discontinued for 3 months. Twenty-five patients (69.4\%) receiving additional formula and complementary nutrition during monitoring were started on elementary formula in addition to breast milk. Healing was achieved with extensively hydrolyzed formula in 17 (68\%) of these and with amino acidbased formula in 8 (32\%).

Improvement in rectal bleeding may be anticipated within 72-96hrs at latest following elimination of the relevant allergen foodstuff [2]. Mean time to resolution of symptoms following commencement of elimination diet in our cases was $6.1 \pm 5.9$ (1-25) days. We think that the mean was raised by the case that failed to respond to mother's diet, that received multiple allergen food stuff elimination and in which breast milk had to be interrupted.

\section{Conclusion}

In conclusion, the current study showed that AP is frequently seen in extensively breastfed infants with a healthy appearance. The allergen most commonly involved was cow's milk protein, and almost all cases resolved at approximately 1 year of age. Good response is achieved to elimination diet, and breast milk may rarely need to be interrupted. To the best of our knowledge, this is the first study to investigate MPV and the NLR in babies with AP. Although no difference was determined compared with the control group, we think that our results can contribute to the literature and that it will be useful for these parameters to be evaluated in further, wider series.

\section{Acknowledgements}

The authors would like to thank Mr. Carl Nino Rossini (a native English speaker) for assistance with the preparation of the manuscript and the correction of the language.

\section{Conflict of Interest}

The authors declare that there is no conflict of interests regarding the publication of this paper.

\section{References}

1. Lack G (2012) Update on risk factors for food allergy. J Allergy Clin Immunolog 129: 1187-1197.

2. Lake AM (2000) Food-induced eosinophilic proctocolitis. J Pediatr Gastroenterol Nutr 30: 558-560.
3. Vandenplas $Y$, Brueton $M$, Dupont $C$, Hill $D$, Oranje $A P$, et al. (2007) Guidelines for the diagnosis and management of cow's milk protein allergy in infants. Arch Dis Child 92: 902-908.

4. Host A (2002) Frequency of cow's milk allergy in childhood. Ann Allergy Asthma Immunol 89: 33-37.

5. Maloney J, Nowak-Wegrzyn A (2007) Educational clinical case seriesfor pediatric allergy and immunology: allergic proctocolitis, food protein-induced enterocolitis syndrome and allergiceosinophilic gastroenteritis with protein-losing gastroenteropa-thy as manifestations of non-IgE-mediated cow's milk allergy. Pediatr Allergy Immunol 18: 360-367.

6. Magazzù G, Scoglio R (2002) Gastrointestinal manifestations of cow's milk allergy. Ann Allergy Asthma Immunol 89: 65-68.

7. Venter C, Brown T, Shah N, Walsh J, Fox AT (2013) Diagnosis and management of non-lgE-mediated cow's milk allergy in infancy-a UK primary care practical guide. Clin Transl Allergy 3: 23.

8. Niggemann B, Beyer K (2007) Diagnosis of food allergy in children: toward a standardization of food challenge. J Pediatr Gastroenterol Nutr 45: 399-404.

9. Hirose R, Yamada T, Hayashida Y (2006) Massive bloody stools in two neonates caused cow's milk allergy. Pediatr Surg Int 22: 935-938.

10. Bone J, Claver A, Guallar I, Plaza AM (2009) Allergic proctocolitis, food-induced enterocolitis: immune mechanisms, diagnosis and treatment. Allergol Immunupathol 37: 36-42.

11. Behjati S, Zilbauer M, Heuschkel R, Phillips A, Salvestrini $C$, et al. (2009) Defining eosinophilic colitis in children: insights from a retrospective case series. J Pediatr Gastroenterol Nutr 49: 208215.

12. Troncone R, Discepolo V (2009) Colon in food allergy. J Pediatr Gastroenterol Nutr 49: 89-91.

13. Winter HS, Antonioli DA, Fukagawa N, Marcial M, Goldman H (1990) Allergy-related proctocolitis in infants: diagnostic usefulness of rectal biopsy. Mod Pathol 3: 5-10.

14. Lozinsky AC, Morais MB (2014) Eosinophilic colitis in infants. J Pediatr 90: 16-21.

15. Perisic VN, Filipovic D, Kokai G (1988) Allergic colitis and rectal bleeding in an exclusively breast-fed neonate. Acta Pediatr Scand 77: 163-164.

16. Fretzayas A, Moustaki M, Priftis KN, Attilakos A, Lapa E, et al. (2011) Thrombocytosis as an overt sign of cow's milk allergic proctocolitis. Allergol Immunopathol (Madr) 39: 381-383.

17. O'Brien CE, Price ET (2013) The blood neutrophil to lymphocyte ratio correlates with clinical status in children with cystic fibrosis: A retrospective study. PLoS One 8: 77420.

18. Kim JY, Park T, Jeong SH, Jeong CY, Ju YT, et al. (2014) Prognostic importance of baseline neutrophil to lymphocyte ratio in patients with advanced papillary thyroid carcinomas. Endocrine 46: 526-531.

19. Tanoglu A, Karagoz E (2014) Predictive role of neutrophil to lymphocyte ratio in Henoch-Schonlein purpura related gastrointestinal bleeding. Rheumatol Int 34: 1331-1332.

20. Makay B, Gücenmez ÖA, Duman M, Ünsal E (2014) The relationship of neutrophil-to-lymphocyte ratio with gastrointestinal bleeding in Henoch-Schonlein purpura. Rheumatol Int 34: 1323-1327. 
21. Morita H, Nomura I, Matsuda A, Saito H, Matsumoto K (2013) Gastrointestinal food allergy in infants. Allergol Int 62: 297-307.

22. Chang JW, Wu TC, Wang KS, Huang IF, Huang B, et al. (2002) Colon mucosal pathology in infants under three months of age with diarrhea disorders. J Pediatr Gastroenterol Nutr 35: 387-390.

23. Chehade $M$ (2007) IgE and non-IgE-mediated food allergy: treatment in 2007. Curr Opin Allergy Clin Immunol 73: 264-268. 